\title{
Role of Palliative Care in Patients with Destination Therapy Left Ventricular Assist Device
}

\author{
Lavanya Bellumkonda \\ Section of Cardiovascular Medicine, Department of Medicine, Yale School of Medicine
}

Received: May 5, 2017; Accepted: May 10, 2017; Published: July 12, 2017

*Corresponding author: Lavanya Bellumkonda, Assistant Professor of Medicine, Yale Center for Advanced Heart failure and Transplantation, 333 Cedar Street, PO Box 208017, New Haven, CT 06520, Tel: 203-785-7191, Fax: 203-785-2917, E-mail: Lavanya.bellumkonda@yale. edu

\begin{abstract}
Left ventricular assist devices (LVAD) have revolutionized care of patients with advanced heart failure. They can be used to bridge a hemodynamically unstable patient to transplant, bridge to transplant (BTT), or offer support to patients who are ineligible for transplant, destination therapy (DT).While these devices improve survival, they can be associated with significant morbidity. Role of palliative care (PC) is ever expanding in the care of patients with LVAD. They should be involved prior to implantation of LVAD, periodically while living with LVAD and during end of life.
\end{abstract}

\section{Introduction}

Patients with advanced heart failure, Stage D heart failure, have very poor prognosis. Those that are inotrope dependent and transplant ineligible have $11-25 \%$ survival at one year [1,2]. While LVAD therapy improves outcome in patients undergoing LVAD implantation as DT, survival is about $58 \%$ and $57 \%$ at 2 and 3 years respectively based on a randomized control study and data from a registry $[3,4]$. Age is a very strong predictor of mortality in various studies [4,5]. Hence this should be taken into consideration while counseling patients prior to LVAD therapy. LVAD therapy is associated with major adverse events such as hemorrhage, stroke and infection, which affect the quality of life. Palliative care consultation in this group of patients is important and strongly recommended by guidelines and mandated by Center for Medicare and Medicaid services, CMS $[6,7]$.

While, palliative care is underutilized in patients with heart failure in general, recent community based studies have shown increasing recognition of the importance of palliative care and hospice care services in patients who are at end of life due to heart failure $[8,9]$. However, similar trends are yet to be seen in patients with LVAD who are at end of life. Despite the well-established mortality rates in these patients and significant adverse effects, a large number of patients with LVAD continue to die in the hospital and most of them in the intensive care. A retrospective cohort analysis of patients at the Mayo clinic showed that while the median time from LVAD to death was 14 months, most of the patients (78\%) died in the hospital with majority $88 \%$ dying in the intensive care. More than half of these patients (55\%) had their LVAD deactivated prior to death [10]. Programs should develop protocols to improve better communications between patients and physicians, continually review the trajectory of their disease, and have greater involvement of PC. Increasing PC involvement would help establish care plans that are consistent with patient's values and goals, thus allowing for greater patient centered outcomes. It would be ideal to have PC role defined during three phases of care in patients with LVAD (Figure 1).

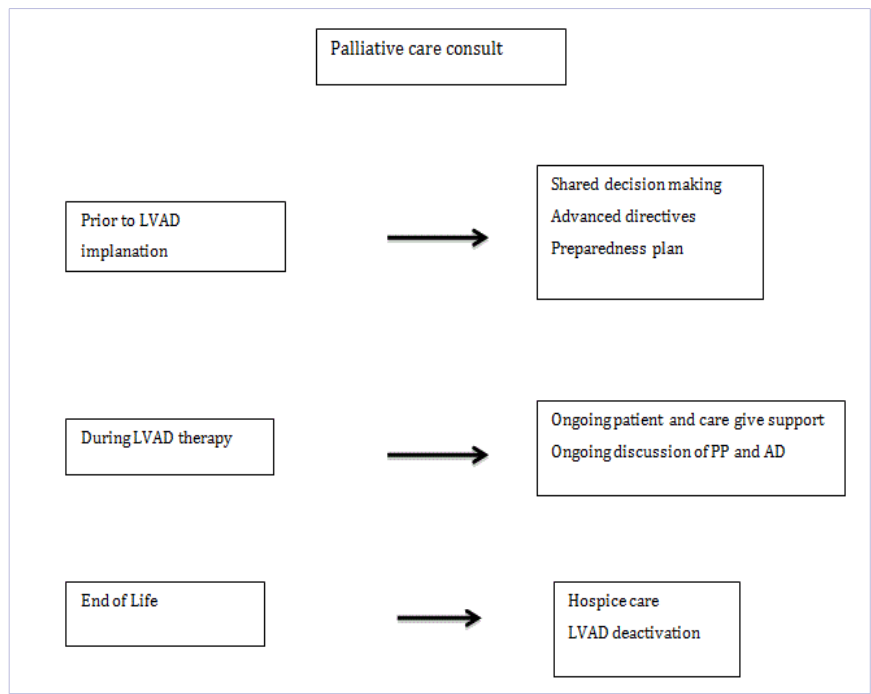

Figure 1: Patient identified as needing LVAD therapy

\section{Prior To LVAD Implantation}

Informed consent should be obtained after detailed discussion of risks and benefits and alternative therapies. Utilizing principles of shared decision-making would be very helpful in this regard. Involvement of the palliative care team in these 
discussions would be beneficial in assessing and addressing the issues of goals of care, advanced directives and providing alternative therapies including ongoing medical management and hospice care. While the LVAD therapy improves survival it is associated with increased risk of complications such as disabling stroke, bleeding, infections, right ventricular failure and repeated hospitalizations [11]. The decision to undergo DT VAD is complicated and involves many considerations including, psychosocial factors, caregiver involvement and burden, emotions considerations including imminent fear of death and the risk of adverse events. Allen et al, have developed decision aids that are both in paper format at 8th grade reading level and video format. These aids deliver standardized information reviewing risks and benefits and highlight the care giver role and burdens of LVAD to help patients understand day-to-day life with LVAD. Swetz et al, have incorporated a preparedness plan (PP) into their counseling and consent process prior to LVAD implantation [12]. A PP is similar to advanced directives, however it is specific for patients with LVAD. PP addresses individual adverse events that are commonly encountered with LVAD therapy and incorporates patients' preferences, which would guide care in each of these circumstances. Patient preferences regarding care after a disabling stroke, need for PEG, prolonged ventilator support, tracheostomy, renal replacement therapy and need for long term dialysis are discussed. A multidisciplinary team comprising of heart failure cardiologist, cardiac surgeon and PC team would be critical for the development of the PP. The heart failure cardiologist and surgeon can provide the necessary information regarding survival and QOL benefits, risk of mortality and patient specific adverse events while the PC team can help patients carve out the PP in accordance with their preferences.

\section{During LVAD Care}

Ongoing consultation with PC team would be helpful to address psychosocial issues, anxiety or depression that patients might experience, address pain management, and review their PP on a periodic basis to see if their views remain consistent with their initial preferences. Most patients and caregivers do not think of death when the QOL is good [13]. PP would be extremely helpful when a major event, either a device related or a non-device related complication occurs or if there is a progressive decline in QOL or functional capacity [12]. When patients experience a decrease in quality of life due to complications and their QOL is no longer in line with their expectations, PC and medical teams should weigh the utility vs. futility of ongoing LVAD support. Based on this assessment, patients should be offered end of life discussions if appropriate [13].

\section{End of Life}

Assessment of futility of LVAD care with onset of major adverse event or a decline in QOL or functional status and initiation of end of life discussions could help with improved patient centered care. Patients that are offered end of life discussion have greater participation in these decisions and to a large extent die outside of the hospital and a majority had their devices turned off compared to those that did not receive end of life counseling
[13]. There is some debate regarding deactivation of the device. There is difference of opinion between physicians caring for these patients and PC physicians regarding ethics of deactivation of LVAD, timing of deactivation, importance of honoring patients' request in this decision when they are not imminently dying, and the ethical and legal aspects of deactivation and if this amounts to euthanasia [14]. However, most experts in the field do not believe deactivation of LVAD amounts to euthanasia, as DT therapy is not considered a replacement therapy [15]. Periodic review of PP with the patient and caregiver will ensure better communication of patient's goals of care and values to all the parties involved and will create less confusion and conflict when decisions regarding end of life and deactivation of LVAD are made. This is especially true if the patient is unable to participate in these discussions due to a serious adverse event.

\section{Conclusions}

While LVAD therapy can be life saving, it is associated with significant change in lifestyle and risk of morbidity. Integrating palliative care early on, using decision aids to educate patients, regular follow up visits with PC to develop and periodically modify preparedness plan as needed, will improve patient participation in the decision making regarding their care $[16,12]$. This will lead to delivery of care that is congruent with their values and goals.

\section{References}

1. Rose EA, Gelijns AC, Moskowitz AJ, Heitjan DF, Stevenson LW, Dembitsky W, et al. Long-term use of a left ventricular assist device for endstage heart failure. N Engl J Med 2001;345(20):1435-1443

2. Rogers JG, Butler J, Lansman SL, Gass A, Portner PM, Pasque MK et al. Chronic mechanical circulatory support for inotrope-dependent heart failure patients who are not transplant candidates: results of the intrepid Trial. J Am Coll Cardiol 2007;50(8):741-747; Doi:10.1016/j. jacc.2007.03.063

3. Slaughter MS, Rogers JG, Milano CA, Russell SD, Conte JV, Feldman D, et al. Advanced heart failure treated with continuous-flow left ventricular assist device. N Engl J Med 2009;361(23):2241-2251; Doi: 10.1056/NEJMoa0909938

4. Kirklin JK, Naftel DC, Pagani FD, Kormos RL, Stevenson LW, Blume ED, et al. Seventh INTERMACS annual report: 15,000 patients and counting. J Heart Lung Transplant 2015;34(12):1495-1504; Doi: 10.1016/j. healun.2015.10.003

5. Cowger J, Sundareswaran K, Rogers JG, Park SJ, Pagani FD, Bhat G, et al. Predicting survival in patients receiving continuous flow left ventricular assist devices: the heartmate II risk score. J Am Coll Cardiol 2013;61(3):313-321; Doi: 10.1016/j.jacc.2012.09.055

6. Decision Memo for ventricular Assist Devices for Bridge-to-Transplant and Destination Therapy (CAG-00432R). 2015

7. Yancy CW, Jessup M, Bozkurt B, Butler J, Casey DE Jr, Drazner MH, et al. 2013 ACCF/AHA guideline for the management of heart failure: executive summary: a report of the American College of Cardiology Foundation/American Heart Association Task Force on practice guidelines. Circulation 2013;128(16):1810-1852; Doi: 10.1161/ CIR.0b013e31829e8807 
8. Beernaert K, Cohen J, Deliens L, Devroey D, Vanthomme K, Pardon K, et al. Referral to palliative care in COPD and other chronic diseases: a population-based study. Respir Med 2013;107(11):1731-1739; Doi: 10.1016/j.rmed.2013.06.003

9. Dunlay SM, Redfield MM, Jiang R, Weston SA, Roger VL. Care in the last year of life for community patients with heart failure. Circ Heart Fail 2015;8(3):489-496; Doi: 10.1161/CIRCHEARTFAILURE.114.001826

10. Dunlay SM, Strand JJ, Wordingham SE, Stulak JM, Luckhardt AJ, Swetz KM. Dying With a Left Ventricular Assist Device as Destination Therapy. Circ Heart Fail 2016;9(10); Doi:10.1161/CIRCHEARTFAILURE.116.003096

11. Hasin T, Marmor Y, Kremers W, Topilsky Y, Severson CJ, Schirger JA, et al. Readmissions after implantation of axial flow left ventricular assist device. J Am Coll Cardiol 2013;61(2):153-163; Doi: 10.1016/j. jacc.2012.09.041

12. Swetz KM, Kamal AH, Matlock DD, Dose AM, Borkenhagen LS, Kimeu AK, et al. Preparedness planning before mechanical circulatory support: a "how-to" guide for palliative medicine clinicians. J Pain Symptom Manage 2014;47(5):926-935 e6; Doi: 10.1016/j.jpainsym- man.2013.06.006

13. Brush S, Budge D, Alharethi R, McCormick AJ, MacPherson JE, Reid BB, et al. End-of-life decision making and implementation in recipients of a destination left ventricular assist device. J Heart Lung Transplant 2010;29(12):1337-1341; Doi: 10.1016/j.healun.2010.07.001

14. Mcilvennan CK, Wordingham SE, Allen LA, Matlock DD, Jones J, Dunlay SM, et al. Deactivation of Left Ventricular Assist Devices: Differing Perspectives of Cardiology and Hospice/Palliative Medicine Clinicians. J Card Fail 2016; S1071-9164(16)31237-4. Doi: 10.1016/j.cardfail.2016.12.001

15. Swetz KM, Ottenberg AL, Freeman MR, Mueller PS. Palliative care and end-of-life issues in patients treated with left ventricular assist devices as destination therapy. Curr Heart Fail Rep 2011;8(3):212-218; doi: 10.1007/s11897-011-0060-x

16. Thompson JS, Matlock DD, mcilvennan CK, Jenkins AR, Allen LA. Development of a Decision Aid for Patients With Advanced Heart Failure Considering a Destination Therapy Left Ventricular Assist Device. JACC Heart Fail 2015;3(12):965-976; Doi: 10.1016/j.jchf.2015.09.007 